\title{
Pouring from an Empty Cup: The Case for Compassion Fatigue in Higher Education
}

\author{
Millie Cordaro, PhD, LPC \\ Texas State University
}

\begin{abstract}
Background: With the global pandemic, higher education has experienced unparalleled changes with abrupt transitions to remote and online learning. Faculty are working to provide continuity of teaching and support to students whose lives have been disrupted; therefore, faculty are finding themselves managing distressed students with a wide range of issues, while also managing their own intrapersonal stress. Consequently, faculty may experience feelings of being psychologically overwhelmed and emotionally exhausted.

Aim: This article informs faculty in higher education on the concept of compassion fatigue along with the symptoms, warning signs, and risk factors. In addition, protective factors, including self-care plans and coping strategies are addressed.

Methods: A comprehensive review of the literature on compassion fatigue was conducted including the application of the construct to teaching and education. The literature review illuminates the use of compassion fatigue, originating from the scientific disciplines of counseling and traumatology, within an emerging line of research findings occurring amongst educators prior to the COVID-19 pandemic.

Results: The literature demonstrates that compassion fatigue as a prospective, intrapersonal condition may potentially affect some faculty in higher education, and the proposed conceptual application of the construct to teaching and education can assist with acknowledging and understanding an important aspect of faculty mental health.

Conclusions: Given the crisis surrounding the pandemic, it's essential for faculty to be aware of compassion fatigue in order to mitigate potential intrapersonal psychological and emotional consequences. Elucidating the symptoms and implications of compassion fatigue for faculty in higher education is part of a broader, overlooked issue on faculty mental health and wellness.
\end{abstract}

Submitted 15 April 2020: accepted 28 May 2020

Keywords: compassion fatigue, teaching, higher education, pandemic, faculty mental health

These are unprecedented times in higher education. Within a few short weeks, the life and school routines for both faculty and students have been disrupted due to the COVID-19 pandemic. With a sense of urgency from an insidious emergency, faculty have worked through the stressful and chaotic process of pivoting to remote teaching, a shared experience throughout college and university communities. With institution-wide online classes underway during the pandemic, new and disconcerting social implications are unfolding. Students have been forced to leave behind their former collegiate lives, and endure other potentially stressful transitions and experiences: dispersing from residence halls; job loss or job-related schedule changes; the loss of in-person campus support; the loss of social support from 
college friends and roommates; technological issues due to displacement; COVID-19 illnesses; caretaking of ill family members, and in some instances grieving the death of a loved one. There are some students who are adequately functioning despite adverse circumstances. For other students, these changes have brought about increased stressors beyond their coping skills; in response, some faculty are actively increasing their support and availability. Moreover, these faculty are developing a deeper regard or concern for those students whose life pathways have taken a turn for the worse. Faculty are also managing new pandemic-related personal stressors. In the midst of the turmoil, a new occupational hazard for empathic instructors is likely to emerge as a result of exposure to student stressors and adversity. This potential threat could manifest from within one's personhood (Stanghellini \& Rosfort, 2013), affecting the mental health of faculty, specifically, their emotions and general well-being.

Deeply caring for distressed students can be a major source of faculty stress, and this stress can potentially heighten amidst the pandemic. The literature is long-standing in the observation that people can become distressed or traumatized by others' hardships (Killian, 2008). In fact, several studies have documented that individuals can be traumatized directly, as well as indirectly via secondary traumatic stress (Stamm, 2010). Secondary traumatic stress is defined as the emotional impact of vicariously dealing with another's trauma (Fleming et. al., 2020). In other words, knowing that someone close to you is experiencing trauma, can potentially be traumatic for you (Figley, 2002). For example, receiving information that a former student or colleague experienced complications related to COVID-19, or died as a result of the virus can be experienced as secondary traumatic stress. The majority of faculty in higher education care to some degree about their students, and it is this positive regard for students that needs protection as well. The pandemic is not without psychological consequences for all. Whether it is transitioning the role of teacher from a classroom or lab space to the online environment, the social disruption implications of the pandemic can potentially create additional layers of complexity in faculty work lives. As faculty continue to practice varying degrees of social distancing around the world, they are also managing additional personal responsibilities: home-schooling children; added household chores; sharing home-based workspace with a spouse or partner; worrying over the health and well-being of aging parents and family members; or struggling with self-isolation. The pandemic has potentially affected faculty by compounding routine, job-related stressors with their students' own traumas. Specifically, to be emotionally present, accessible, and supportive to students in order to provide continuity in teaching and learning can create additional stressors for faculty. For empathic educators working with distressed students, there is a possibility of becoming vulnerable to a specific type of secondary trauma, i.e., compassion fatigue (Hoffman, Palladino, \& Barnett, 2007). The aim of this article is to bring the notion of compassion fatigue to the forefront as a faculty mental health issue that some will experience while working and teaching in the higher education profession during the current crisis.

\section{COMPASSION FATIGUE CONCEPTUALIZATION}

Compassion fatigue encompasses secondary traumatic stress and is described as the experience of feeling psychological stress brought on by listening and being exposed to the details of another's distressful circumstances (Figley, 1995). Originating from the mental health literature, specifically traumatology, the construct was developed out of a necessity to identify why helping professionals were being negatively affected by providing emotional support to their clients (Figley, 1995). However, the term is not exclusive to those working within the field of traumatology as it has been applied to a wide range of professions (Yang \& Kim, 2012), including teaching (Hoffman, Palladino, \& 
Barnett, 2007). While most faculty are not affiliated with the helping professions, they are being cast into a helping role. With empathy playing a central role in the onset of compassion fatigue (Figley, 2002), it is defined as an empathic strain or general exhaustion that comes from working with the distressed over time (Figley, 1995; Turgoose \& Maddox, 2017). With ongoing emotional, physical, or mental exhaustion, compassion fatigue can impede feelings of empathy and concern for others (Figley, 2002). Due to the nature of COVID-19, some faculty may exhibit a psychological vulnerability toward developing compassion fatigue by bearing witness to students who are distressed, struggling with mental health issues, or experiencing trauma in their lives. By simply caring and exercising empathy toward students, faculty can become psychologically overwhelmed. Given the circumstances surrounding the pandemic, faculty will naturally want to provide comfort to students while juggling family obligations and other personal demands; in turn, becoming susceptible to compassion fatigue long before their career is over.

\section{COMPASSION FATIGUE SYMPTOMOLOGY}

Symptoms of compassion fatigue have been documented in the literature, and are important for faculty to be aware of in order to buffer against their potential impact in themselves and their colleagues. In general, compassion fatigue can be experienced by anyone in a helping role that still has the desire to give support despite feeling overwhelmed by stressors belonging to someone else (Branson, 2019).

Providing emotional support to those experiencing trauma can lead to psychological symptoms of compassion fatigue: physical or emotional exhaustion; continuous mental involvement in others' issues; feelings of being overwhelmed or helpless; and feelings of sadness, grief, depression, anxiety, dread, fear, or emotional numbness. More features related to compassion fatigue include experiencing poor self-esteem, guilt for enjoying oneself, engaging in alcohol or drug use, or experiencing relational issues (Figley, 2002a; Fleming et al., 2020; Sabery, Tafreshi, Hosseini, Mohtashami, \& Ebadi, 2019). Faculty would be well served to take note should they begin to experience such negative affect, or find themselves engaging in numbing or addictive behaviors. In fact, in some cases, compassion fatigue experienced as secondary traumatic stress can mirror the clinical features of posttraumatic stress disorder (PTSD) including hyperarousal, avoidance, or intrusive thoughts or memories vicariously internalized from someone else's trauma and pain (Bride, 2004; Turgoose \& Maddox, 2017). Last, the inability to provide emotional support or empathy within one's own personal relationships due to job-related emotional exhaustion is another warning sign to consider.

Cognitive symptoms of compassion fatigue are prevalent as well. These symptoms can affect one's meaningmaking system (i.e., guiding principles on how one connects within themselves and with others, and how individuals make sense of their life events) ranging from moral or philosophical dilemmas to questioning of one's existential meaning and spirituality in the midst of a disaster (Figley, 2002b; Lahad, 2000; Pearlman \& Saakvitne, 1995). Therefore, if a faculty member begins to question or feel cynical about their life's purpose and meaning in either their personal or professional lives due to distress, it can be a warning sign that despite best intentions they are emotionally and psychologically overwhelmed. Compassion fatigue does encompass burnout as well, which entails a gradual onset of feelings of hopelessness and diminished job satisfaction and productivity (Bhutani, Bhutani, Balhara, \& Kalra, 2012; Soderfelt \& Soderfelt, 1995). 


\section{RISK FACTORS FOR COMPASSION FATIGUE}

Several risk factors have been empirically linked to the onset of compassion fatigue. Being aware of these risk factors can assist faculty with targeting self-care and coping strategies to protect themselves against the harmful psychological consequences of compassion fatigue (Hensel, Ruiz, Finney, \& Dewa, 2015).

Neglecting one's self-care has been cited as a risk factor for developing compassion fatigue (Ray, Wong, White, \& Heaslip, 2012), and like other professions, offsetting student-care with self-care can be a challenge for some (Can $\&$ Watson, 2019). Given that there has been a long-standing stigma that self-care is self-indulging or a personal luxury, it can prove challenging for some to make the paradigm shift (Carroll, Gilroy, \& Murra, 1999). Figley (2002a) phrased compassion fatigue as "the cost for caring," and faculty need to be mindful that ignoring one's emotional or psychological needs can lead to negative outcomes. As the euphemism lightly suggests, "you can't pour from an empty cup."

Another risk factor for compassion fatigue is porous professional boundaries (Abendroth \& Flannery, 2006). Prior to the pandemic, the issue to be addressed would be the professional and physical boundaries that faculty maintain with students in order to achieve a personal satisfactory work-life balance. However, with the viral outbreak and consequent life disruption, faculty collectively have been practicing social distancing, which defaulted them into a physical distance from students. Ironically, despite the physical boundary, the cognitive appraisal of the situation and our emotional response still needs addressed via a professional boundary. In other words, faculty should practice psychologically distancing themselves from their students at times to protect their emotional well-being. Otherwise, as previously noted, allowing the mind to be continuously preoccupied by the distress of students would be both emotionally and mentally taxing (Sabery et al., 2019). It is a delicate dance of being emotionally connected to students while maintaining a salient and separate sense of self, especially in times of a far-reaching crisis.

One's age is another risk factor associated with compassion fatigue, in that as individuals mature throughout their lifespan, they tend to become more psychologically robust (Adams, Matto, \& Harrington, 2001). Other studies report that females are at a greater risk for compassion fatigue than males (Meyers \& Cornille, 2002), and those with a personal trauma history are more susceptible to secondary traumatic stress and compassion fatigue (Nelson-Gardell $\&$ Harris, 2003). As a final risk factor, research has shown that inadequate personal (O’Neill \& Morrow, 2001) or professional support puts employees at a greater risk for compassion fatigue (Boscarino, Figley, \& Adams, 2004).

Collectively, these risk factors can be considered benchmarks as faculty members ascertain their own susceptibilities to compassion fatigue. It is important to note that these risk factors were generally identified in the literature as occurring outside the context of a far-reaching crisis or catastrophic event (Sprang, Clark, \& WhittWoosley, 2007). In other words, while research supports that these risk factors were present prior to and during other crises, such as the 9/11 terrorist attacks (Tosone, Bettmann Schaefer, Minami, \& Jasperson, 2010), it is hypothesized that these risk factors will be ubiquitous across many disciplines and professions due to the COVID-19 crisis as well.

\section{PROTECTIVE FACTORS AS COPING STRATEGIES FOR COMPASSION FATIGUE}

Contemporary literature has noted several protective factors that reduce the likelihood of developing compassion fatigue. These protective factors can be applied as proactive coping strategies (e.g., preventatively coping in advance) or as intervention coping strategies once compassion fatigue is suspected. Given that neglectful self-care was previously identified as a risk factor for compassion fatigue, the antithesis (i.e., actively engaging in strategic self-care 
interventions) has been shown to increase satisfaction and well-being (Hotchkiss \& Lesher, 2018), and decrease compassion fatigue, secondary trauma stress, and burnout (Alkema, Linton, \& Davies, 2008).

Self-care is defined as positive activities that help to manage stress and it is associated with positive physical health, mental health and emotional well-being (Shapiro, Brown \& Biegel, 2007; Cook-Cotton \& Guyker, 2018). Lee and Miller (2013) proposed that self-care should address both the personal and professional self to holistically maintain or optimize psychological health and well-being. In fact, self-care has been documented in the literature as a central component of preventing or mitigating professional-related stress (Grise-Owens, Miller, Escobar-Ratliff, \& George, 2018); yet, self-care is commonly considered to be an individual responsibility (Christopher, Christopher, Dunnagan, \& Schure, 2006). Therefore, an effective, all-encompassing self-care routine that is used as a means of stress reduction can help prevent or minimize the effects of compassion fatigue (Hotchkiss \& Lesher, 2018). Faculty are encouraged to think through a broad range of self-care activities (e.g., gardening; exercising; accessing mental health resources in order to learn stress reduction techniques; good sleep hygiene and quality sleep; learning about emotion and problem-focused coping) as a way to maintain adequate to optimal psychological functioning and be intentional about applying them in their professional and personal lives.

Self-compassion is a more recently discovered construct coined by Neff (2003, p.224)) as "being kind and understanding toward oneself during instances of pain or failure, rather than being harshly self-critical, and recognizing that one's own experience of imperfection is a part of the human experience." In other words, we recognize our own distress, without judgement, while attempting to alleviate it (Beaumont, Durkin, Hollins Martin, \& Carson, 2016; Gilbert, 2009). Practicing self-compassion has been empirically correlated with psychological wellbeing (Boellinghaus, Jones, \& Hutton, 2012; Germer \& Siegel, 2012), and individuals who practice self-compassion are at less risk for compassion fatigue and burnout (Beaumont et al., 2016; Thompson, Amatea, \& Thompson, 2014). In fact, self-compassion is one of the strongest predictors of both personal and professional self-care practices (Miller, Lee, Niu, Grise-Owens, \& Bode, 2019). Thus, faculty can utilize self-compassion as a metacognitive (i.e., thinking about one's thinking) coping strategy (Neff, 2003), whereby faculty are able to identify that the kindness, understanding, and concern they extend to students should be reciprocated toward oneself and that any psychological discomfort or pain that's seen in others should not be treated any less empathically within themselves.

One self-care strategy for practicing self-compassion is through loving-kindness meditation (LKM) (Boellinghaus, Jones, \& Hutton 2013). Loving-kindness meditation involves practicing mindfulness (Tang, Hölzel, \& Posner, 2015) with a mental state of unconditional kindness, warmth and caring toward all, including ourselves (Hoffman, Grossman, \& Hinton, 2011; Totzeck, 2020). Germer and Neff (2013) created an evidenced-based program to bring mindful self-compassion (MSC) to the general population through teaching a variety of meditations including LKM. As a coping strategy, LKM has been shown to foster positive emotions (Carson et al., 2005). Free audio and written meditations can be downloaded at www.CenterForMSC.org.

A second protective factor that functions as a coping strategy to minimize stress reactions and mitigate compassion fatigue is social support. Specifically, having a positive social support network and a professional social support network are key for coping during stressful work periods (O’Neill \& Morrow, 2001). In these times, these social networks are connecting virtually via Zoom, or by phone or email. A central aspect of effective social support is the perception that one feels understood when seeking support from another (Figley, 2013). Therefore, being intentional about individuals to whom faculty might go to help fulfill emotional needs that foster the experience of feeling valued is key. This buffers against or minimizes the impact of stress. According to the social convoy model 
(Antonucci, Ajrouch, \& Birditt, 2014), each person should aim to have an intimate social sphere comprised of friends and family members that share in one's life accomplishments and challenges. As we get older, our social convoy will retract over time because adults become more selective about the people they invest their time in, but the benefits of this group will provide a protective layer against stress. With social distancing, it is especially important to be intentional about connecting to one's social convoy in order to access positive social support in faculty members' personal lives. It is important to note that some faculty may experience symptoms that are so intense that they undermine a faculty member's ability to function and carry out daily duties and responsibilities. In this case, faculty members should seek the support of a helping professional.

As part of broader university-wide wellness initiatives, some college and university communities are providing online trainings, workshops, virtual meetups, and mental health resources to help faculty navigate both their personhood and professional self through these tumultuous times. Amaya et al. (2019) proposed a "call to action" for academic institutions to implement systemic initiatives that promote the health and well-being for all in the academic community: students, faculty, and staff. Given the COVID-19 pandemic, it is paramount for academic institutions to acknowledge the importance of faculty mental health as a central aspect of student engagement and success (Kennette \& Lin, 2019). In addition, faculty need to utilize the resources available to them. Faculty can practice self-care in the professional realm by accessing their institution's social support network and resources. Chatting with colleagues in your department or colleagues that you enjoyed collaborating with on projects (i.e., social convoy) or across disciplines via institution-wide offerings can create a space and outlet to be understood, valued, and supported. Giving a voice to professional inner struggles that other faculty can relate to will help to minimize the impact of compassion fatigue. Check with your faculty development center, university counseling center or inquire about employee wellness and/or assistance programs through your Human Resources department. For instance, since faculty began teaching remotely, the Faculty Development center at Texas State University has been offering a Friday, "Let's Do Lunch" series, allowing faculty across departments to talk about the toils of online teaching; thus addressing and validating the importance of faculty well-being. Considering these options and inquiring if one is appropriate for you is good selfcare. Participating in institution-wide, college, or departmental peer-to-peer support will assist with adaptive coping and help to buffer against stress, so that you can continue to provide students with your support well after the pandemic is over.

\section{CONCLUSION}

Higher education has been forced into an expedition across uncharted territory due to the sweeping COVID-19 pandemic. While trying to preserve continuity in teaching and learning, instructors are also managing intrapersonal stress, along with a range of distressed students and their issues. Faculty who are feeling physically, mentally, or emotional overwhelmed or exhausted due to their students' trauma or burdens may be experiencing compassion fatigue. In order to prevent or lessen the effects of compassion fatigue, faculty can adopt self-care routines and adaptive coping strategies, and actively engage them. Creating a "menu" of self-care options for oneself that brings a sense of equanimity (i.e., mental calmness) should be devised, and ideally these options should be written out for future use. Practicing self-compassion while leaning into one's personal social convoy and professional social support network and resources is key as well. Last, faculty need to evaluate their internal (e.g., emotional and psychological) boundaries, and practice psychologically distancing oneself from interpersonal burdens if they find themselves 
preoccupied with the issues of others. Mindfulness activities and meditation and/or prayer are effective coping strategies that can help to focus thoughts while reducing stress (Kabat-Zinn, 2005; Donahoo, Siegrist, \& GarrettWright, 2018; Spinelli, Wisener, \& Khoury, 2019), and in turn can bolster self-compassion (Rabb, 2014). However, if rumination (i.e., repetitive negative thinking) occurs along with other severe symptoms that are undermining one's ability to effectively function then faculty should seek help from a mental health professional.

Acknowledging the effects of compassion fatigue for faculty in higher education is part of a broader, overlooked subject on faculty mental health and wellness. Faculty personhood encompasses the psychological and emotional dimensions of being human that we take with us into the classroom with our students. Feeling psychologically overwhelmed or experiencing emotional distress can illicit consequences for all aspects of the faculty job role, especially teaching effectiveness. Higher education institutions need to consider the mental health and well-being of their faculty. The COVID-19 pandemic will require most faculty to practice self-care and effective coping strategies in order to effectively engage with students. Otherwise, faculty will be pouring from an empty cup. 


\section{REFERENCES}

Abendroth, M., \& Flannery, J. (2006) Predicting the risk of compassion fatigue: A study of hospice nurses. Journal of Hospice and Palliative Nursing, 8(6), 346-356. https://doi.org/10.1097/00129191-200611000-00007

Adams, K. B., Matto, H. C, \& Harrington, D. (2001). The traumatic stress institute belief scale as a measure of vicarious trauma in a national sample of clinical social workers. Families in Society: The Journal of Contemporary Human Services,82, 363-371. https://doi.org/10.1606/1044-3894.178

Alkema,K.,Linton,J.M.,\& Davies,R. (2008). A study of the relationship between self-care, compassion satisfaction compassion fatigue, and burnout among hospice professionals. Journal of Social Work in End-of-Life and PalliativeCare,4(2), 101-119. https://doi.org/10.1080/15524250802353934

Amaya, M., Donegan, T., Conner, D., Edwards, J., \& Gipson, C. (2019). Creating a culture of wellness: A call to action for higher education, igniting change in academic institutions. Building Healtby Academic Communities Journal, 3(2). 27-40. https://doi.org/10.18061/bhac.v3i2.7117

Antonucci, T. C., Ajrouch, K. J., \& Birditt, K. S. (2014). The convoy model: Explaining social relations from a multidisciplinary perspective. The Gerontologist, 54(1), 82-92. https://doi.org/10.1093/geront/gnt118

Beaumont, E., Durkin, M., Hollins Martin, C.J., Carson, J. (2016). Measuring relationships between self-compassion, compassion fatigue, burnout and well-being in trainee counsellors and trainee cognitive behavioural psychotherapists: a quantitative survey. Counselling and Psychotherapy Research. 16(1): 15-23. https://doi.org/10.1002/capr.12054

Bhutani, J., Bhutani, S., Balhara, Y. P., \& Kalra, S. (2012). Compassion fatigue and burnout amongst clinicians: A medical exploratory study. Indian journal of psychological medicine, 34(4), 332-337. https://doi.org/10.4103/0253-7176.108206

Boellinghaus, I., Jones, F. W., \& Hutton, J. (2013). Cultivating self-care and compassion in psychological therapists in training: The experience of practicing loving-kindness meditation. Training and Education in Professional Psychology, 7(4), 267-277. https://doi.org/10.1037/a0033092

Boellinghaus, I., Jones, F.W., \& Hutton, J. (2012). The role of mindfulness and loving-kindness meditation in cultivating self-compassion and other-focused concern in health care professionals. Mindfulness, 5, 129-138. https://doi.org/10.1007/s12671-012-0158-6

Boscarino, J. A., Figley, C. R., \& Adams, R. E. (2004). Compassion fatigue following the September 11 terrorist attacks: A study of secondary trauma among New York social workers. International Journal of Emergency Mental Health, 6, 110.

Branson, D. C. (2019). Vicarious trauma, themes in research, and terminology: A review of literature. Traumatology, 25(1), 2-10. https://doi.org/10.1037/trm0000161

Bride, B. E. (2004). The impact of providing psychosocial services to traumatized populations. Stress, Trauma and Crisis: An International Journal, 7, 29-46. https://doi.org/10.1080/15434610490281101

Can, N., \& Watson, J. (2019). Individual and Relational Predictors of Compassion Fatigue among Counselors-inTraining. The Professional Counselor, 9, 285-297. https://doi.org/10.15241/nc.9.4.285 
Carroll, L., Gilroy, P., \& Murra, J. (1999). The moral imperative: Self-care for women psychotherapists. Women \& Therapy, 22(2), 133-143. https://doi.org/10.1300/J015v22n02_10

Carson, J. W., Keefe, F. J., Lynch, T. R., Carson, K. M., Goli, V., Fras, A. M., \& Thorp, S. R. (2005). Lovingkindness meditation for chronic low back pain: Results from a pilot trial. Journal of Holistic Nursing, 23, 287304. https://doi.org/10.1177/0898010105277651

Christopher, J. C., Christopher, S. E., Dunnagan, T., \& Schure, M. (2006). Teaching self-care through mindfulness practices: The application of yoga, meditation, and qigong to counselor training. Journal of Humanistic Psychology, 46(4), 494-509. https://doi.org/10.1177/0022167806290215

Cook-Cottone, C.R, \& Guyker, W.M. (2018). The development and validation of the mindful self- care scale (MSCS): An assessment of practices that support positive embodiment. Mindfulness, 9, 161-175. https://doi.org/10.1007/s12671-017-0759-1

Donahoo, L.M., Siegrist, B., \& Garrett-Wright, D. (2018). Addressing Compassion Fatigue and Stress of Special Education Teachers and Professional Staff Using Mindfulness and Prayer. The Journal of School Nursing, 34, 442-448. https://doi.org/10.1177/1059840517725789

Figley, C. R. (1995). Compassion fatigue as secondary traumatic stress disorder: An overview. In C. R. Figley (Ed.), Compassion fatigue: Coping with secondary traumatic stress disorder in those who treat the traumatized (pp. 1-20). New York, NY: Brunner-Routledge.

Figley, C. R. (2002a). Compassion fatigue: Psychotherapists' chronic lack of self-care. Journal of Clinical Psychology, 58,1433-1441. https://doi.org/10.1002/jclp.10090

Figley, C. R. (Ed.). (2002b). Treating compassion fatigue. Routledge.

Figley, C. R. (Ed.). (2013). Compassion fatigue: Coping with secondary traumatic stress disorder in those who treat the traumatized. Routledge. https://doi.org/10.4324/9780203777381

Fleming, K., Mazzatta, G. R., Matarese, K., \& Eberle, J. (2020). Compassion fatigue and the ART model. Nursing, 50(3), 58-61. https://doi.org/10.1097/01.NURSE.0000654168.38494.dd

Germer, C.K., \& Siegel, R.D. (Eds.) (2012). Wisdom and compassion in psychotherapy: Deepening mindfulness in clinical practice. Guildford Press.

Germer, C. K., \& Neff, K. D. (2013). Self-compassion in clinical practice. Journal of Clinical Psychology, 69(8), $856-867$. https://doi.org/10.1002/jclp.22021

Gilbert. P. (2009). The Compassionate Mind. London: Constable.

Grise-Owens, E., Miller, J.J., Escobar-Ratliff, L., \& George, N. (2018). Teaching note-teaching self-care and wellness as a professional practice skill: A curricular case example. Journal of Social Work Education, 54, 180 186. https://doi.org/10.1080/10437797.2017.1308778

Hensel, J. M., Ruiz, C., Finney, C., \& Dewa, C. S. (2015). Meta-analysis of risk factors for secondary traumatic stress in therapeutic work with trauma victims. Journal of Traumatic Stress, 28, 83-

91. https://doi.org/10.1002/jts.21998 
Hoffman, S., Palladino, J., \& Barnett, J. (2007). Compassion fatigue as a theoretical framework to help understand burnout among special education teachers. Journal of Ethnographic and Qualitative Research, 2, 5-22.

Hofmann, S. G., Grossman, P., \& Hinton, D. E. (2011). Loving-kindness and compassion meditation: Potential for psychological interventions. Clinical Psychology Review, 31(7), 1126-1132. https://doi.org/10.1016/j.cpr.2011.07.003

Hotchkiss, J. T.. \& Lesher, R. (2018). Factors predicting burnout among chaplains: Compassion satisfaction, organizational factors, and the mediators of mindful self-care and secondary traumatic stress. Journal of Pastoral Care and Counseling 72(2), 86-98. https://doi.org/10.1177/1542305018780655

Kabat-Zinn, J. (2005). Bringing mindfulness to medicine: An interview with Jon Kabat-Zinn, PhD, Interview by Karolyn, A. Gazella. Advances in Mind-Body Medicine, 21(2), 22-27.

Kennette, L. N., \& Lin, P. S. (2019). Focusing on faculty stress. Transformative Dialogues: Teaching \& Learning Journal, 12(1), 1-4.

Killian, K. D. (2008). Helping till it hurts? A multimethod study of compassion fatigue, burnout, and self-care in clinicians working with trauma survivors. Traumatology, 14, 32-44. https://doi.org/10.1177/1534765608319083

Lahad, M. (2000). Darkness over the abyss: Supervising crisis intervention teams following disaster. Traumatology, 6(4), 273-293. https://doi.org/10.1177/153476560000600403

Lee, J. J., \& Miller, S. E. (2013). A self-care framework for social workers: Building a strong foundation for practice. Families in Society, 94 (2), 96-103. https://doi.org/10.1606/1044-3894.4289

Meyers, T. W. \& Cornille, T. A. (2002). The trauma of working with traumatized children. In C. R. Figley (Ed.), Treating compassion fatigue (Vol. 24, pp. 39-55). Routledge.

Miller, J.J., Lee, J., Niu, C., Grise-Owens, E., \& Bode, M. (2019). Self-compassion as a predictor of self-care: A study of social work clinicians. Clinical Social Work Journal 47, 321-331. https://doi.org/10.1007/s10615-01900710-6

Neff, K. (2003). The development and validation of a scale to measure self-compassion. Self and Identity, 2, $223-250$. https://doi.org/10.1080/15298860309027

Nelson-Gardell, D., \& Harris, D. (2003). Childhood abuse history, secondary traumatic stress, and child welfare workers. Child Welfare, 82 (1), 5-27.

O’Neill E.S. \& Morrow L.L. (2001) The symptom experience of women with chronic illness. Journal of Advanced Nursing, 33(2), 257-268. https://doi.org/10.1111/j.1365-2648.2001.01653.x

Pearlman, L. A., \& Saakvitne, K. W. (1995). Treating therapists with vicarious traumatization and secondary traumatic stress disorders. In C. R. Figley (Ed.), Brunner/Mazel psychological stress series, No. 23. Compassion fatigue: Coping with secondary traumatic stress disorder in those who treat the traumatized (p. 150-177). Brunner/Mazel.

Raab, K. (2014) Mindfulness, self-compassion, and empathy among health care professionals: A review of the literature. Journal of Health Care Chaplaincy, 20(3), 95-108. https://doi.org/10.1080/08854726.2014.913876 
Ray, S. L., Wong, C., White, D., \& Heaslip, K. (2013). Compassion satisfaction, compassion fatigue, work life conditions, and burnout among frontline mental health care professionals. Traumatology, 19 (4), 255-267. https://doi.org/10.1177/1534765612471144

Sabery, M., Tafreshi, M.Z., Hosseini, M., Mohtashami, J., \& Ebadi, A. (2019). Development and psychometric assessment of risk factors of compassion fatigue inventory in nurses. Journal of Nursing Measurement, 27(2), 6280. https://doi.org/10.1891/1061-3749.27.2.E62

Shapiro, S.L., Brown, K.M., \& Biegel, G.M. (2007). Teaching self-care to caregivers: Effects of mindfulness-based stress reduction on the mental health of therapists in training. Training and Education in Professional Psychology, 1(2),105-115. https://doi.org/10.1037/1931-3918.1.2.105

Soderfelt, M., \& Soderfelt, B. (1995). Burnout in social work. Social Work. (40)6, 38-47.

Spinelli, C., Wisener, M., \& Khoury, B. (2019). Mindfulness training for healthcare professionals and trainees: A meta-analysis of randomized controlled trials. Journal of Psychosomatic Research, 120, 29-38. https://doi.org/10.1016/j.jpsychores.2019.03.003

Sprang, G., Clark, J. J., \& Whitt-Woosley, A. (2007). Compassion fatigue, compassion satisfaction, and burnout: Factors impacting a professional's quality of life. Journal of Loss and Trauma, 12(3), 259-280. https://doi.org/10.1080/15325020701238093

Stamm, B. H. (2010). The concise ProQOL manual (2nd ed.). Retrieved from http://proqol.org

Stanghellini, G., \& Rosfort, R. (2013). Emotions and personhood: Exploring fragility-making sense of vulnerability. OUP Oxford. https://doi.org/10.1093/med/9780199660575.001.0001

Tang, Y.Y.; Hölzel, B.K.; Posner, M.I. (2015). The neuroscience of mindfulness meditation. Nature Reviews Neuroscience, 16, 213-225. https://doi.org/10.1038/nrn3916

Thompson, I.A., Amatea, E.S., \& Thompson, E.S. (2014). Personal and contextual predictors of mental health counselors' compassion fatigue and burnout. Journal of Mental Health Counselling, 36(1), 58-77. https://doi.org/10.17744/mehc.36.1.p61m73373m4617r3

Tosone, C., Bettmann Schaefer, J., Minami, T., \& Jasperson, R. (2010). New York City social workers after 9/11: Their attachment, resiliency, and compassion fatigue. International Journal of Emergency Mental Health. 12, 10316.

Totzeck, C., Teismann, T., Hofmann, S. G., Von Brachel, R., Pflug, V., Wannemüller, A., \& Margraf, J. (2020). Loving-kindness meditation promotes mental health in university students. Mindfulness, 11. https://doi.org/10.1007/s12671-020-01375-w

Turgoose, D., \& Maddox, L. (2017). Predictors of compassion fatigue in mental health professionals: A narrative review. Traumatology, 23(2), 172-185. https://doi.org/10.1037/trm0000116

Yang, Y. H., \& Kim, J. K. (2012). A literature review of compassion fatigue in nursing. Korean Journal of Adult Nursing, 24, 38-51. https://doi.org/10.7475/kjan.2012.24.1.38 
Address author correspondence to:

Millie Cordaro, PhD, LPC

Department of Psychology

Texas State University

601 University Drive, San Marcos, Texas, United States 78666-4684

mc71@txstate.edu 